\section{Games and Terrorism}

\section{Recent Developments}

\author{
Todd Sandler \\ Kevin Siqueira \\ University of Texas at Dallas, USA
}

Simulation \& Gaming Volume XX Number X Month XXXX xx-Xx (C) 2008 Sage Publications $10.1177 / 1046878108314772$ http://sg.sagepub.com hosted at http://online.sagepub.com

\begin{abstract}
This article provides an updated survey of recent advances in game-theoretic analyses of terrorism. In particular, it investigates the government's allocation of a fixed budget to counter attacks against potential targets. The choice between proactive and defensive countermeasures is addressed, along with the impact that domestic politics has on this choice. Other topics include the interaction between political and militant factions within terrorist groups, the role of asymmetric information, and game-theoretic analysis of suicide terrorism. Throughout, the article highlights surprising results from the application of game theory. Unanswered questions are also indicated.
\end{abstract}

Keywords: asymmetric information; backlash terrorism; defensive countermeasures; game theory; militant factions; proactive countermeasures; suicide attacks; terrorism

Sinct ince Sandler, Tschirhart, and Cauley (1983) put forward a game-theoretic model of the negotiation process between terrorists and government policy makers, the application of game theory to the study of terrorism has grown, with contributions in economics and political science. This application greatly increased following alQaida's four skyjackings on September 11,2001. The primary purpose of this review is to focus on recent articles regarding the application of game theory to the study of terrorism, to highlight insights and their importance. In so doing, this study is highly selective in focusing on key articles. As such, the current survey complements but does not duplicate an earlier survey by Sandler and Arce (2003). In accomplishing our task, we emphasize the modeling strategies rather than the full modeling details.

Terrorism is the premeditated use of violence or the threat of violence by individuals and subnational groups to obtain a political or social objective through the intimidation of a large audience beyond that of the immediate victims. Game theory is an appropriate tool to capture the strategic interactions among various agent pairings: the terrorists and the government, two or more targeted countries, rival terrorist

Authors' Note: This research was partially supported by the U.S. Department of Homeland Security through the Center for Risk and Economic Analysis of Terrorism Events at the University of Southern California, Grant No. 2007-ST-061-000001. However, any opinions, findings, and conclusions or recommendations are solely ours and do not necessarily reflect the views of Department of Homeland Security. We have profited from comments by Daniel G. Arce, Hirofumi Shimizu, and Jun Zhuang. 
groups, and terrorists and their supporters. Other, less-obvious player combinations include military and political wings of a terrorist group, terrorists and a state sponsor, and terrorists and the media. Interactions may involve three players-for example, two targeted countries and the terrorists or the voters, the country's policy maker, and the terrorists. Both noncooperative and cooperative game theory can be used to study terrorism. Thus far, most analyses involve noncooperative game theory, for which players have no way to enforce agreements except through threat-based (e.g., tit-fortat) strategies in an infinitely repeated game framework. Cooperative game theory is germane to understanding terrorist and government networks. Relevant noncooperative games can include simultaneous play (e.g., targeted governments deciding which potential targets to secure) and sequential play (e.g., a government hardening targets, followed by terrorists deciding which target to attack).

Some essential messages permeate our investigation. First, addressing one or more strategic interaction means eschewing an analysis of other strategic interactions. Models must be made tractable so that a choice of players must be made; that is, conclusions may drastically change as the strategic players change. Generally, just two or three strategizing players are considered at a time. Second, the use of multiple stages allows for more strategic players, but in each stage, there are generally two kinds of actively strategizing agents. Third, the number of continuouschoice variables is limited; thus, a new continuous-choice variable requires making some other variable into a discrete-choice variable. Fourth, game-theoretic analyses of terrorism yield results that may be counterintuitive; for instance, augmenting information about terrorists' targeting preferences may actually exacerbate the inefficient behavior of targeted governments. Once the underlying strategic interaction is understood, the findings become intuitive. As a tool, game theory allows one to uncover nonobvious insights.

The body of this article is organized in terms of seven topics of recent concern, addressed in the ensuing seven sections. Each section conceptualizes the question being addressed and distills some important insights reached thus far. To promote brevity, the relevant literature is, in some sections, displayed in a table. The final section summarizes and provides a brief discussion of some unanswered questions.

\section{Allocating Counterterrorism Resources Among Potential Targets}

Counterterrorism comes in two basic varieties: defensive policies and proactive measures. Defensive policies protect potential targets by making attacks costly for terrorists and by reducing their likelihood of success. Effective defensive actions also limit society's losses. The installation of metal detectors in airports on January 5, 1973, to screen airline passengers is an apt example of a defensive measure. 
Counterterrorism also takes the form of proactive and offensive actions that affect the terrorists directly. Such policies include government operations to curtail terrorists' resources, finances, safe havens, and sponsors. For example, terrorists' resources can be reduced by capturing or killing group members and by destroying their nonhuman resources, such as weapons, ammunition, training camps, and communication assets.

In this section, we focus on defensive decisions whereby a government must allocate a fixed amount of defensive resources, $D$, among $N$ potential targets. Theoretical and empirical analyses identify a substitution phenomenon whereby efforts to harden one target induce terrorists to shift to alternative targets (Enders \& Sandler, 1993, 2004). Thus, metal detectors in airports resulted in a precipitous fall in skyjackings, coupled with a huge increase in other kinds of hostage-taking incidents (e.g., kidnappings). Defensive measures cause terrorists to respond in a predictable fashion.

In recent years, the most important insight concerning defensive allocations comes from allowing the terrorists and their targeted governments to be strategic players who respond to each other's choice variables. Following Powell (2007), suppose that a government has two targets to protect, as denoted by $i=1,2$. At target $i$, the government must consider the likelihood of an attack $\left(p_{i}\right)$, the loss in case of a successful attack $\left(L_{i}\right)$, and the vulnerability of the site $\left(v_{i}\right)$. The probability of an attack on Site 1 or 2 is $p_{1} \geq 0$ and $p_{2} \geq 0$, with $p_{1}+p_{2}=1$. The vulnerability indicates the probability that an attack on this site and target will succeed. As such, $v_{i}$ negatively depends on defensive resources allocated to this site such that $v_{i}^{\prime}\left(d_{i}\right)<0$. The expected loss at target $i$ is the product $p_{i} L_{i} v_{i}\left(d_{i}\right)$ so that a government with two atrisk targets chooses $d_{1}$ to

$$
\min \left[p_{1} L_{1} v_{1}\left(d_{1}\right)+p_{2} L_{2} v_{2}\left(D-d_{1}\right)\right]
$$

with first-order condition

$$
p_{1} L_{1} v_{1}^{\prime}\left(d_{1}^{*}\right)=p_{2} L_{2} v_{2}^{\prime}\left(d_{1}^{*}\right)
$$

This first-order condition indicates that the defender allocates protective resources between sites to equate marginal reduced losses. If the analysis stops here, then the allocation will not be optimal, because terrorists' calculated choice of site probabilities, $p_{1}$ and $p_{2}$, must also be considered; that is, the attacker chooses $p_{1}$ to

$$
\max \left[p_{1} G_{1} v_{1}\left(d_{1}\right)+\left(1-p_{1}\right) G_{2} v_{2}\left(d_{2}\right)\right],
$$

where $G_{i}$ is the terrorists' gain at target $i$. Resource allocation by the government is independent of $G_{i}$ because the government presumably does not know terrorists' 
preferences. Clearly, the two opponents' choices are interdependent and so must be solved together.

To illustrate the importance of strategic players, we use Figure 1, slightly modified from Powell's interesting analysis (2007), in which the defender's expected loss is on the vertical axis and $d_{1}$ is on the horizontal axis. If the terrorist group is treated nonstrategically, then the defender's loss is minimized at $d^{*}$, where the group does not adjust its attack strategy based on the defender's choice; that is, the defender continues to bolster protection at Site 1 until the loss, displayed by the thicker parabola, is minimized. This allocation does not account for the terrorist group's altering its attack probabilities by shifting its interests to Site 2 as $d_{1}$ increases and $d_{2}$ decreases. The strategic behavior is captured in Figure 1 by the intersecting curves depicting the strategic, marginal expected losses to Sites 1 and 2 . When $d_{1}=0$, the defender's marginal expected loss to Site 1 is the greatest, and its marginal expected loss to Site 2 is zero because the latter is so well defended. As $d_{1}$ grows, Site 1 becomes a less attractive target for the terrorists relative to Site 2. Consequently, the marginal expected loss to Site 1 declines and that to Site 2 increases. The strategic equilibrium is at $\left(\hat{d}_{1}, D-\hat{d}_{1}\right)$ the intersection of the two thinner curves. As drawn, $\hat{d}_{1}<d_{1}^{*}$ so that the strategic reactions of the terrorists cause the defender to divide its resources differently, with less focus on one site. A recent article by Farrow (2007) indicated resource allocation among targets under various interesting scenarios; however, the terrorist group is not a strategic player in his model.

Powell (2007) presented an $N$ target version of his analysis, with a loss function for the government, $L(d, p)$, and a gain function for the terrorist group, $G(d, p)$, where $d=\left(d_{1}, \ldots, d_{N}\right)$ and $p=\left(p_{1}, \ldots, p_{N}\right)$. These loss and gain functions sum the expected losses and gains, respectively, over the $N$ sites. An algorithm involving minimax is used to solve the game. Powell goes on to consider border defenses versus site defenses, as well as dividing resources to protect against terrorist and natural disasters.

Bier, Oliveros, and Samuelson (2007) and Zhuang and Bier (2007) effectively extended Powell's work (2007) by allowing for more variable interdependency; for example, an attacker's or a defender's evaluation of the gains and losses from terrorist operations depends on attack effort, $a=\left(a_{1}, \ldots, a_{N}\right)$, and the target's defense, $d=\left(d_{1}, \ldots, d_{N}\right)$, at each potential target. The defender maximizes its expected utility, $U_{D}(a, d)$, while the attacker maximizes its expected utility, $U_{A}(a, d)$. These expected utilities account for the probability of damage $\left(p_{i}\right)$ at site $i$, which itself depends on $a_{i}$ and $d_{i}$. Moreover, $U_{A}$ and $U_{D}$ include the disutility, or cost, of the attacker's total effort and the defenders' total protective investment over all sites, respectively.

At least five initially counterintuitive results follow from Bier et al. (2007) and Zhuang and Bier (2007). First, the attacker's actions may rise with the defender's actions if the players' reaction paths with $a$ and $d$ on the axes are strategic complements; 
Figure 1

Defense Decision in a Strategic and Nonstrategic Scenario

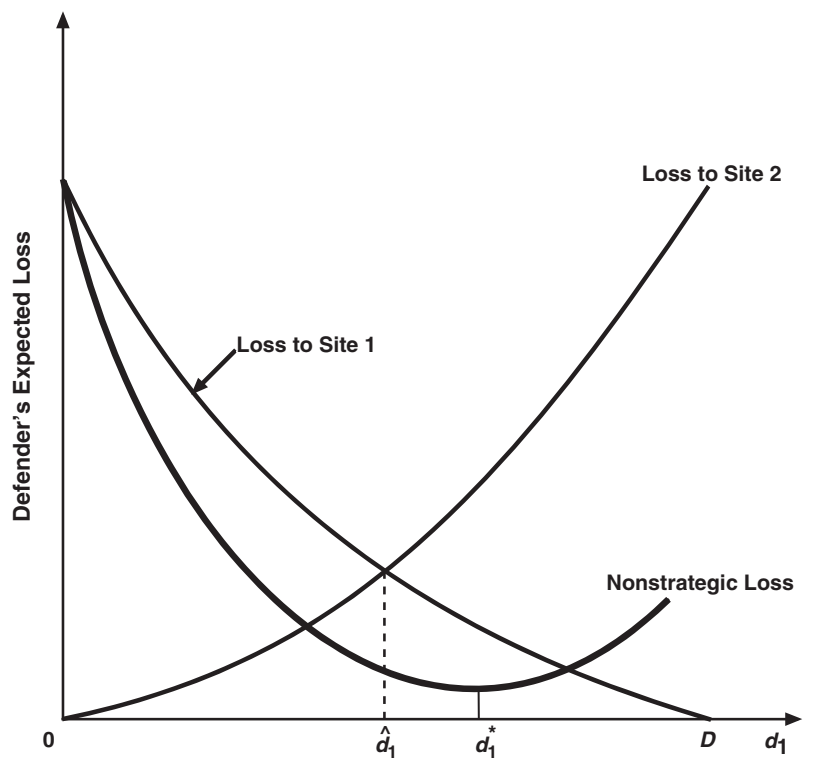

that is, an arms race may characterize the attacker's and the defender's actions where greater defenses result in more effort from the attacker, up to some maximal level and vice versa. As a consequence, heightened defenses may reduce welfare for both adversaries, which would then imply that the adversaries can mutually benefit from a cease-fire. Second, these articles show that the defender has a strategic advantage in moving first because its welfare is at least as great in the sequential game as it is in the simultaneous game. By moving first, the defender can entice the terrorists to hit relatively less valuable targets, provided that terrorists know which targets are hardened. Third, it may behoove the government to make its defensive outlays public, something that is not always understood by officials. ${ }^{1}$ Fourth, these articles, as well as those by Farrow (2007) and Lee (2007), show that some potential targets may be left undefended because the expected losses to the government is not that great and defensive resources are scarce. The notion that weakest links must be shored up everywhere does not necessarily hold. Fifth, border defenses must be considered in conjunction with individual site defenses insofar as border security reduces the vulnerability of all sites. 
The first article on target defense allocation is that by Sandler and Lapan (1988), which made the two targets be the strategic players and the terrorist group be the passive (nonstrategic) player. Nevertheless, it is the first to show that centralized policy making results in more optimal allocations than does decentralized decision making. This latter finding has been rediscovered in many recent contributions (e.g., Bier et al., 2007; Lee, 2007; Zhuang \& Bier, 2007) without recognizing its antecedent almost two decades prior. Sandler and Lapan highlighted the need to choose among the potential pairings of strategic players because it is difficult to allow three independent strategic players at the same stage of a game without making other limiting assumptions. The authors focused on target governments to show that they must cooperate, or else the terrorists will benefit. They also built a sufficiently rich model to allow for the overprovision and underprovision of defensive measures based on the target country's mix of interests at home and abroad. Interests in multicountry targets are absent for recent studies in which the terrorist group and a centralized government are the strategic players. Sandler and Lapan showed that information and intelligence are not always a good thing, because they may exacerbate counterproductive defense races among targeted governments once they know terrorists' attack proclivities.

Zhuang and Bier (2007) criticized other articles for, at times, making the target decision discrete; yet, they made losses discrete (i.e., losses are complete or zero). This just served to illustrate that relaxing one assumption requires tightening another. Generalization comes at a cost in terms of increased specialization. For example, Zhuang and Bier did not look at transnational terrorism in which multiple countries are strategic players.

Table 1 summarizes the modeling strategies and key findings of six essential studies on allocating resources among competing targets. This line of inquiry is particularly germane to homeland security, which requires allocation principles (not pork barrel politics) for distributing grants among states and locales. These grant distributions fail to recognize that not all localities need protecting.

In these mostly defensive studies, the proactive and defensive policy mix has been investigated in a rather artificial way that essentially treats each decision as independent. Proactive responses that weaken the terrorists surely influence defensive strategies and vice versa. Many proactive measures need to be imposed only once against a common terrorist threat, while defensive measures must be applied every period that the threat remains. The sequencing of these two classes of countermeasures must be addressed.

\section{Proactive and Defensive Countermeasures}

For domestic terrorism, we observe that nations often employ a judicious mix of proactive and defensive policies. Thus, France broke up Direct Action; Italy ended 


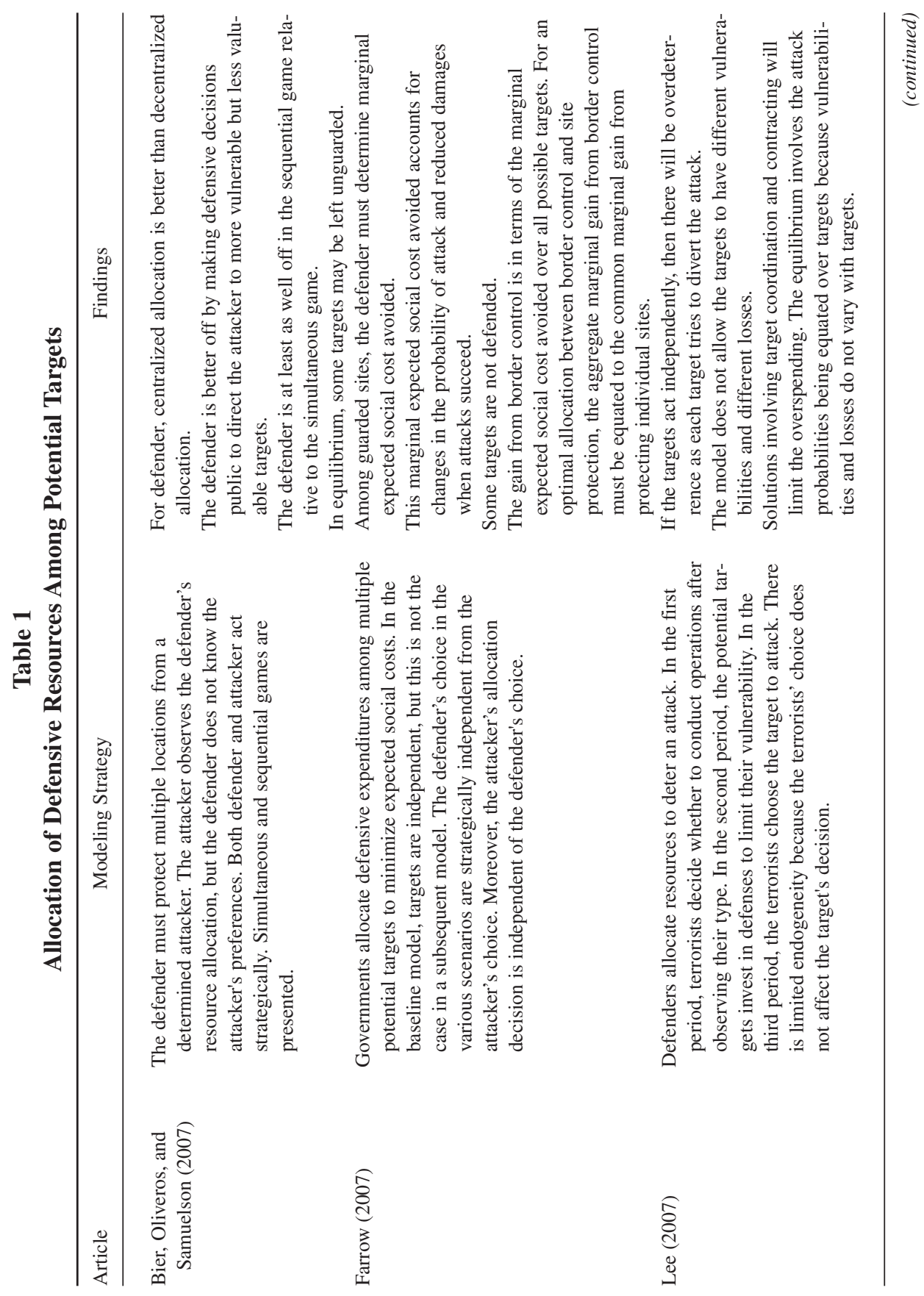




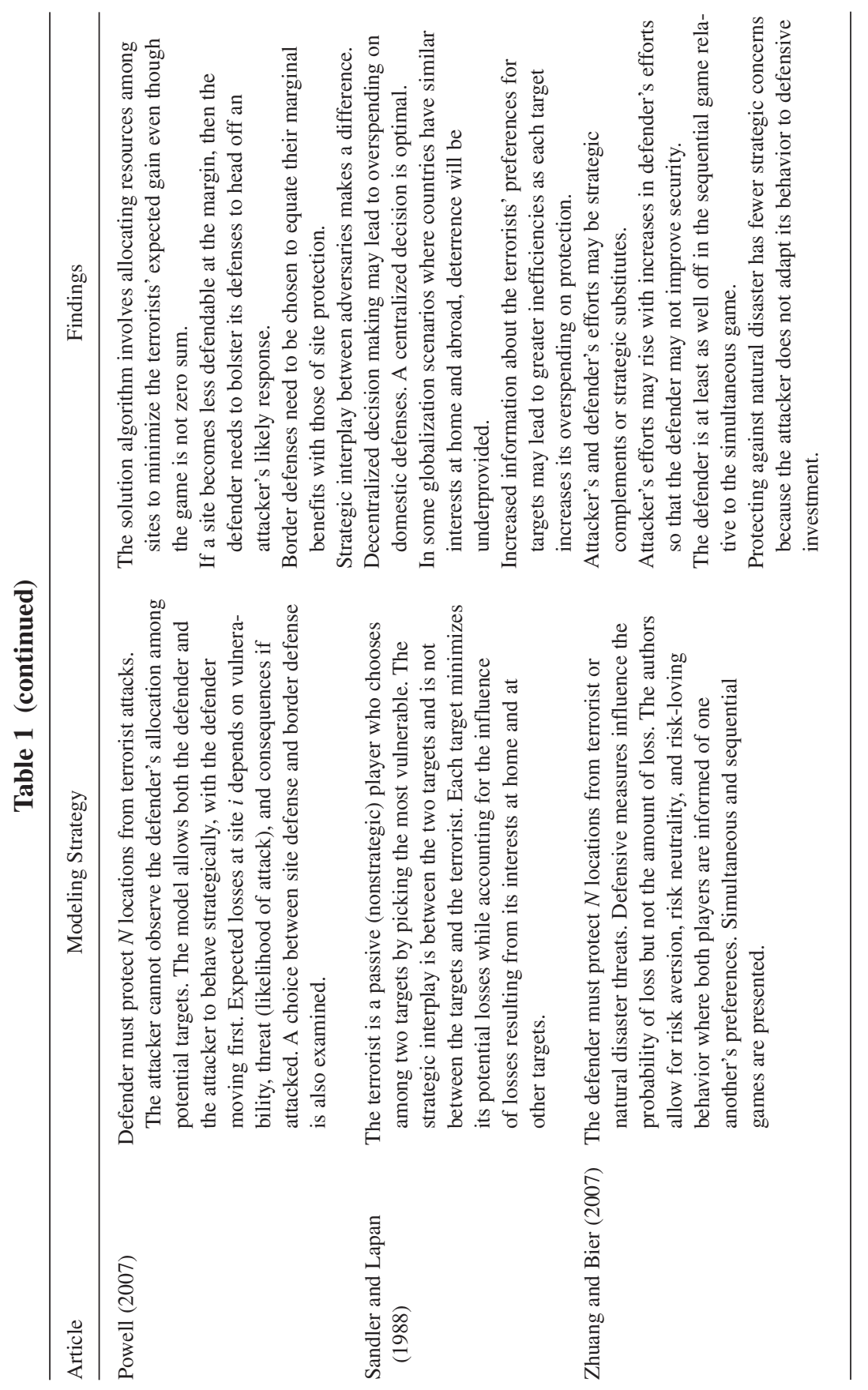


the Italian Red Brigades; West Germany captured the leaders of Baader-Meinhof Group; and Belgium stopped the Combatant Communist Cells (Alexander \& Pluchinsky, 1992; Enders \& Sandler, 2006; Hoffman, 2006). Israel deploys proactive and defensive measures against Hamas and Hezbollah, whose recent attacks are primarily directed at Israel. In the case of transnational terrorism where two or more countries are targeted by the same group (e.g., al-Qaida), countries are inclined to use defensive measures in the hopes that a prime-target country will eliminate the threat for everyone. This pattern can be easily explained.

In Figure 2, we depict a $3 \times 3$ normal-form game representation for two countries facing a common terrorist threat. Each country has three strategies: augment its defense to limit terrorism, take proactive measures against the terrorists, do nothing (i.e., status quo). We investigate the game by first examining the embedded defensive and proactive games separately. We initially focus on the northwest $2 \times 2$ boldbordered matrix where each nation can take an offensive response at a private cost of $c$ for a public benefit of $B$, received by both countries. When both take offensive measures, each nation gains $2 B$ from the combined responses and nets $2 B-c$. We assume that $2 B>c>B$ so that we have a prisoner's dilemma (Tucker 1950/2001) with a dominant strategy to do nothing and a Nash equilibrium at mutual inactivity with payoff $(0,0)$ for Nations 1 and 2 , respectively. Each nation gets a net negative payoff of $B-c$ as it puts its military in harm's way for the benefit of all.

Next, we turn to the southeast $2 \times 2$ bold-bordered matrix, where nation $i$ hardens its targets at a cost of $C$ to itself for a private benefit of $b>C$. This action by $i$ results in a spillover cost for the other nation of $C_{j}$ that arises as $i$ 's defensive measures divert the attack abroad to the now-softer target. When both countries defend their home targets, nation $i$ nets $b-C-C_{i}<0$ because it must pay its defense cost of $C$ and incur the loss of $C_{i}$ in not being a necessarily less attractive target once the other country defends, if the terrorist is bent on attacking someone. As before, we assume an inequality, $C+C_{i}>b>C$ for $i=1,2$ that results in a prisoner's dilemma. The dominant strategy for both nations is to defend given that $b-C>0$, resulting in a Nash equilibrium at mutual defense.

Finally, we turn to the entire $3 \times 3$ game to find the Nash equilibrium. The payoff combinations for (proact, defend) and (defend, proact) can be easily filled in as displayed. For both nations, the dominant strategy is to defend because the payoffs are higher than the corresponding payoffs associated with the other two strategies, given that $b-C>0>B-c$. The sole Nash equilibrium is at mutual defense, indicated by the boldfaced payoffs. Of the two embedded Nash equilibriums, the worst reigns. In fact, the payoffs at this Nash equilibrium is the smallest summed payoff of the nine strategic combinations! Arce and Sandler (2005) demonstrated the resilience of this result. If, for instance, a fourth strategy of instituting both proactive and defensive responses is added, the Nash equilibrium of the $4 \times 4$ matrix (not shown) is still to specialize in defensive measures. If, however, one nation is a prime target that attracts the lion's share of the terrorist attacks, then its benefits from 
Figure 2

A $3 \times 3$ Proactive-Defensive Game

\begin{tabular}{|c|c|c|c|c|}
\hline & & \multicolumn{3}{|c|}{ nation 2} \\
\hline \multirow{4}{*}{ 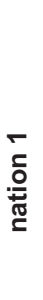 } & & Proactive & Status quo & Defend \\
\hline & Proactive & $2 B-c, 2 B-c$ & $B-c, B$ & $B-c-C_{1}, B+b-C$ \\
\hline & Status quo & $B, B-C$ & 0,0 & $-C_{1}, b-C$ \\
\hline & Defend & $B+b-C, B-c-C_{2}$ & $b-C,-C_{2}$ & $b-c-c_{1}, b-c-c_{2}$ \\
\hline
\end{tabular}

$(2 B>c>B)$ and $\left(C+C_{\mathrm{i}}>b>C\right), \mathrm{i}=1,2$

unilateral offense may sufficiently increase that it takes offensive measures affording others a free ride (Arce \& Sandler, 2005).

\section{Strategic Substitutes and Strategic Complements}

To distinguish strategic differences between proactive and defensive measures, we briefly sketch a generic model that serves to represent both kinds of policies. Once again, we assume that two nations, $i=1,2$, are targeted by the same terrorist group. In any given period, the terrorist group can stage its attack in a single country. Each country has interests at home $(h)$ and abroad $(a)$. We treat the terrorist group as a passive player who hits the more opportunistic target. Government $i$ chooses its policy instrument to increase the likelihood of a terrorist failure at home, denoted by $\theta_{i}$. In essence, $\theta_{i}$ is related in a $1-1$ fashion to a proactive or defensive measure. The main difference between these measures hinges on the form of the probability function that government $i$ is attacked, given by $\pi_{i}\left(\theta_{i}, \theta_{j}\right)$. In the case of defensive measures, we have $\partial \pi_{i} / \partial \theta_{i}<0$ and $\partial \pi_{j} / \partial \theta_{i}>0$ because $i$ 's defensive measures reduce the risk of attack to $i$ but increases these risks to $j$. Diminishing returns to efforts ensure that $\partial^{2} \pi_{i} / \partial \theta_{i}^{2}>0$ and $\partial^{2} \pi_{j} / \partial \theta_{i}^{2}<0$. Furthermore, country $j$ 's defensive efforts reduce (increase) the marginal impact of country $i$ 's action to limit the probability of being attacked at home when $j$ 's efforts are greater (less) than those of $i$, so that $\partial^{2} \pi_{i} / \partial \theta_{i} \partial \theta_{j} \gtreqless 0$ as $\theta_{j} \gtreqless \theta_{i}$. For a proactive measure, we have $\partial \pi_{i} / \partial \theta_{i}<0$ and $\partial \pi_{j} / \partial \theta_{i}<0$ because offense against a common terrorist threat reduces everyone's likelihood of attack. With sufficient proactive efforts, no attack may ensue. Once again, there are diminishing returns to effort resulting in the two direct second-order partials being positive. Because proactive measures are substitutable, we have that 
$\partial^{2} \pi_{i} / \partial \theta_{i} \partial \theta_{j}>0$ for all scenarios. That is, $j$ 's actions reduce the marginal impact of $i$ 's proactive efforts.

Each country independently minimizes its costs, which can arise from three sources: policy expense, $E\left(\theta_{i}\right)$; nation $i$ 's expected damage from a home attack, $\pi_{i} l_{h}\left(\theta_{i}\right)$; and nation $i$ 's expected damage from an attack abroad, $\pi_{j} l_{a}\left(\theta_{j}\right)$. That is, nation $i$ choose $\theta_{i}$ - either defensive or proactive measures- to

$$
\min C_{i}\left(\theta_{i}, \theta_{j}\right)=E\left(\theta_{i}\right)+\pi_{i}\left(\theta_{i}, \theta_{j}\right) l_{h}\left(\theta_{i}\right)+\pi_{j}\left(\theta_{i}, \theta_{j}\right) l_{a}\left(\theta_{j}\right) .
$$

An identical expression holds for nation $j$.

Sandler and Siqueira (2006) established that reaction paths, $\theta_{i}\left(\theta_{j}\right)$ and $\theta_{j}\left(\theta_{i}\right)$, for defensive policies are positively sloped for a reasonable set of assumptions. ${ }^{2}$ Thus, defensive choices move together, indicative of strategic complements, whereas the reaction paths for proactive efforts are negatively sloped, reflective of strategic substitutes. ${ }^{3}$ A nation's independent choice of $\theta_{i}$ and $\theta_{j}$ fails to account for costs and benefits conferred on the other country. For example, a target's independent choice of defense does not include the increased risks of attack-based diversion imposed abroad or the augmented safety afforded to foreign residents at home. For proactive measures, a nation's independent choice ignores the increased safety afforded to the other nation's interests at home and abroad. Thus, defensive action may be oversupplied or undersupplied depending on these opposing benefits and costs, whereas proactive measures are invariably undersupplied.

\section{Leadership}

We next turn to the notion of leadership where one targeted nation assumes the initiative to act first. For example, a prime-target country may be the first to offensively confront the terrorists. Similarly, some countries may act first to bolster security - for example, the United States' defensive measures after September 11. Leadership is displayed theoretically by having the leader, say $i$, consider the best response function, $\theta_{j}\left(\theta_{i}\right)$, of the follower as a constraint so that the leader minimizes $C_{i}\left[\theta_{i}, \theta_{j}\left(\theta_{i}\right)\right]$ and the follower acts as it did before. For the leader, we replace $\theta_{j}\left(\theta_{i}\right)$ wherever $\theta_{j}$ appears in Equation 4; in so doing, the leader accounts for the reaction of the follower. The leader thus anticipates that its provision causes the follower to reduce its proactive effort. This, in turn, results in the leader reducing its offensive efforts to shift more burden onto the follower. The result is that the leader does less, the follower does more, and overall proactive efforts go down. This surprising finding indicates that leadership does not promote a stronger proactive stance.

When defensive measures are strategic complements, leadership actually cuts down on any oversupply. This follows because the leader realizes that its efforts will stimulate more actions to harden targets abroad. By accounting for this possibly self-defeating reaction, the leader sensibly restrains its fortification efforts. Unlike 
proactive measures, leadership can reduce inefficient allocations. For counterterrorism measures, the impact of leadership is tied to the notion of strategic substitutes and complements.

\section{Choosing Between Proactive Versus Defensive Measures}

Bandyopadhyay and Sandler (2007) investigated the choice between proactive and defensive measures by constructing a two-stage game in which each of two targeted countries chooses a proactive response in the first stage and a defensive effort in the second stage. The proactive choice is initially modeled as preceding the defensive action because an effective proactive decision may eliminate the terrorist threat from then on, thereby lessening or eliminating the need for defense. These authors show that the mix between these two policies hinges on three key factors: the policies' cost comparisons, the countries' foreign interests, and the countries' targeting risks. Low proactive costs are not sufficient to determine the proactive country, because defense costs and/or prime-target status can overcome the influence of comparatively low proactive costs. A high-cost defender will suffer from period to period until the terrorist threat is eliminated. Moreover, countries with greater interests abroad have higher effective marginal defense costs, which bolster their application of offensive measures. In practice, prime-target countries with long borders and a high level of foreign direct investment are likely to go after a common terrorist threat, a prediction that indeed fits the United States and the United Kingdom following September 11. These long borders and/or high trade levels mean that border defense expenses are relatively high. The authors' analysis highlights that studying proactive and defensive counterterrorist responses in isolation provides an incomplete picture.

In game theory, the order of stages or plays can affect the outcome. Thus, one must worry whether the outcome sketched above would change had the defensive decision preceded the proactive choice. Bandyopadhyay and Sandler (2007) demonstrated that altering the sequence of choices does not qualitatively affect the results. The staging assumption is not driving the finding insofar as each decision has a strictly dominant strategy (e.g., to undersupply proactive measures). Elementary game theory teaches that strict dominance leads to games where the order of moves does not matter.

\section{Other Aspects of Defensive and Proactive Counterterrorism}

Heal and Kunreuther (2005) highlighted an important aspect of defensive actions where an agent's overall security hinges on everyone's actions, owing to interdependent risks. ${ }^{4}$ The safety of a commercial flight from an onboard bomb depends on the screening vigilance of all airlines connected with the passengers, crew, and luggage on a flight. Pan Am Flight 103 in December 1988 was brought down over Lockerbie, Scotland, by a bomb in luggage transferred from a flight from Malta. Airlines do not rescreen luggage from feeder flights. "Failures of any element of an interdependent 
system can have devastating impacts on all parts of the system" (p. 201). This interdependency somewhat limits the motivation to take due diligence because one's own care is not the sole determinant of one's fate. These authors put forward interesting public policies that direct resources to where security augmentation has the greatest influence on inducing others to exercise greater care. For airline travel, those carriers with the most feeder flights are the logical candidates for security assistance because such efforts have the greatest impact on augmenting systemwide safety. As is common, the authors investigated defensive decisions in isolation.

For proactive policies, Rosendorff and Sandler (2004) formulated a game where both the targeted government and the terrorists are strategic players. Proactive policy now has a dark side by increasing grievances if it is too harsh. This policyinduced increased grievance augments terrorist recruitment, which can result in large-scale incidents known as spectaculars. A two-stage model is presented where the government first chooses the proactive level, and it is followed by the terrorists, who pick the level of attack. The authors' analysis indicates that spectacular events are encouraged by either too meek or too strong a proactive response, thus presenting the government with a dilemma to choose the proper intermediate response.

\section{Domestic Politics and Terrorism}

Despite government officials' wishes to the contrary, counterterrorism policy comes under public scrutiny and influence. The terrorism literature has recently considered the role of domestic politics and counterterrorism policy. The addition of voters to the interaction between policy makers and terrorists not only adds another strategic agent but may also require analyzing the game in a multistage setting. Besides fostering reality, this addition permits more interesting and subtle interactions among policy stakeholders.

To capture the influence of domestic politics on government counterterrorism efforts, Siqueira and Sandler (2007) focused on the problem of delegation where voters choose policy makers in two democratic countries that face a common terrorist threat. Policy makers determine the level of effort to devote to proactive measures to reduce the general threat from terrorist group $A$. Offensive actions taken by one country can increase the likelihood of its being attacked by terrorist group $B$, which attacks the country that exerts the greatest counterterrorism effort. Group $B$ objects to the countermeasures and may be motivated by grievances. Voters in each country share objectives with their policymakers and only differ in the weight that they place onto the threat of experiencing a backlash attack at home.

The timing of this multistage game is as follows. In Stage 1, voters in each country simultaneously and independently elect their policy maker, who then implements a level of proactive effort in Stage 2. Voters and governments are assumed to know the terrorists' preferences but are unsure about their propensity to engage in violent 
acts. In Stage 3, terrorist group $A$ decides whether to wage its campaign against the two countries, and as a potential reaction to government countermeasures, terrorist group $B$ surfaces and attacks the heavier-handed country. The subgame perfect equilibrium is found by backward induction. When voters choose their policy makers in the first stage, they account for the effect that their choices have on the actions of policy makers and terrorists in subsequent stages of the game.

Because proactive measures represent a public good, there is a tendency, mentioned earlier, that such efforts will be underprovided because of free riding. Within the present context, however, there is also the risk of a backlash attack and the problem of delegation. The latter arises because voters have an incentive to strategically elect a government that puts a different weight on the general terrorist threat, in the hopes of shifting abroad more of the offensive response, thereby augmenting free riding and limiting a backlash attack. Strategic voting may result in fewer overall proactive measures and a greater general terrorism threat. For counterterrorism policy, the inclusion of domestic politics illustrates the potential dilemma that democracies face when trying to address a common terrorist threat (Wilkinson, 1986).

The above results need not hold in all circumstances (Siqueira \& Sandler, forthcoming). When government counterterrorism efforts are strategic complements, domestic political considerations can actually curb each country's tendency to engage in overly excessive spending on defensive countermeasures intended to transfer the attack abroad. In the first stage, voters have a strategic incentive to limit transference efforts by electing a policy maker who places less weight than that of the typical voter on the expected damages from a terrorist attack. With delegation, countries possess incentives to commit to smaller defensive countermeasures.

Bueno de Mesquita (2007) also included domestic politics into his analysis of government counterterrorism policies and, unlike Siqueira and Sandler (2007, forthcoming), allowed the government to possess a strategy set that differs on two dimensions: generality and observability. Tactic-specific defensive policies are readily observable by voters, who reward policy makers at the polls for taking action. These policies are also observed by terrorists, who can switch tactics according to perceived risks and costs. In contrast, general proactive counterterrorism policies are not readily observable, but such policies limit terrorist opportunism. Because general countermeasures are not observed by voters, government efforts in this dimension may not be directly rewarded. The model's implications are therefore relatively straightforward. The government spends more than what is socially optimal on observable counterterrorism policies. If, however, general unobservable countermeasures prevent terrorist attacks and if voters duly credit policy makers, then the latter still have some incentive to undertake such activities to secure reelection.

Looking at the opposite causality, Garfinkel (2004) showed how an increased external threat of terrorism affects domestic politics. Based on a modified contest success model (or rent-seeking model), Garfinkel's work demonstrated that if a nation's overall sense of security remains low in equilibrium, then an increased 
terrorist threat tends to weaken incentives to engage in domestic dissension and conflict. If, in contrast, the sense of security remains high or does not dissipate too rapidly with an external terrorist threat, then the degree of domestic dissent and domestic conflict may then actually increase.

\section{Terrorist Group Factions and Interactions}

Although numerous insights are obtained from treating terrorist movements and groups as unitary actors in game-theoretic models, the assumption overlooks some key issues regarding the behavior of terrorists and their organizations, such as how rebel movements solve the problem of free riding. As first highlighted by Olson (1965) and later by Tullock (1974), the typical individual has little incentive to join a rebellion, given that the expected public benefits from participating are small relative to the expected private costs. Groups promote membership and collective action through selective private incentives and other institutional design innovations (e.g., monitoring behavior at the local level). Once groups within the movement overcome this hurdle, many interesting issues remain.

Given the tendency of terrorist groups to splinter into separate and independent factions, partial collective action appears to be a good starting point to investigate not only how groups and various factions may interact with one another but also how each faction may react to, and differ in their reactions to, various government counterterrorism policies. Some authors address a few of these concerns in a game-theoretic framework.

Sandler and Arce (2003) presented a simple model of bargaining between a government and a terrorist group with moderate and hard-line members. Given the government's lack of information about the terrorists whom they face, moderate terrorists will mimic hard-liners' attacks to obtain larger concessions from a besieged government. If, however, government concessions are set to placate only moderates, adverse selection will result because moderates are appeased and hardliners resort to violence.

A somewhat different perspective was put forward by Bueno de Mesquita (2005b) in his model of partnership between a government and former terrorists, where the government is uncertain about the level of its partner's efforts to reduce terrorist violence. Given that the government can only observe the outcome of its partner's efforts, it must base its rewards and punishments on its updated beliefs about the former terrorists' actions and their ability to achieve the desired results. Failure to sufficiently reduce violence may result in the former terrorists being replaced as partners by another set of former terrorists. Success, however, may result in the former terrorists' being retained and rewarded by government concessions.

Thus, former terrorists are motivated to exert counterterrorism efforts by the combined threat of punishment and the promise of rewards. There is, however, a slight 
caveat. If the government perceives that the potential replacements are clearly better or worse than its current partners, then the latter are not properly motivated, because their actions have no effect on the government's retention decision. Accordingly, only when potential replacements are of moderate ability will current partners be sufficiently induced into exerting effort. This outcome offers an explanation of why a government may have incentives to nurture equal rival factions within terrorist movements-for example, Israel's initial support of Hamas. Such factions increase the government's leverage at getting the groups to expend greater effort toward reducing terrorism.

The interaction between moderates and extreme elements in a terrorist movement is also germane to Bueno de Mesquita (2005a), who explained why terrorist organizations may become even more violent after receiving government concessions. Governments may still make concessions despite this concern. One part of the problem involves credibility and the government's inability to commit and honor its concessions if both types of factions accept its offers. The government can therefore only hope to draw moderates away from the terrorist movement, thereby leaving extremists in charge of remaining resources. If such resources remain sufficiently large, the level of violence of the terrorist organization can actually increase after concessions. The government thus faces a trade-off between the possible increase in violence that results from the agreement and the enhanced probability of succeeding in their counterterrorism efforts if they obtain assistance from moderate former terrorists.

Another important issue involves the possible competition that can exist among the various factions within terrorist organizations. The failure of factions to cooperate and account for their interdependent actions has important ramifications. Epstein and Gang (2007) developed a model that describes the behavior of fundamentalist sects based on the rents (gains) that leaders earn by attracting a following. Even though strict religious observance is costly, adherents may be better off if observance reinforces their beliefs that they are on the right path and so strengthens their ties to more knowledgeable leaders. In general, fundamentalists and their sects are not terrorists nor terrorist groups; nevertheless, the Epstein and Gang model can be suitably interpreted within a terrorism context to gain further insight. A terrorist leader has incentives to choose a higher level of radicalism when it differentiates his group from an alternative, thereby augmenting adherents and the leader's gain. However, greater radicalism raises the cost of observance, making it more likely that some individuals will leave the group. Although it is unclear which of the two effects dominates, the group's radicalism may increase as members are more exposed to an outside alternative if, as the authors argued, switching costs are high. When further competition from more groups is introduced into the model, the level of radicalism increases.

To prevent switching to another faction, leaders must increase the radicalism of their factions. Although this may decrease total rents for the leaders, rents are higher than what they would be had the leaders remained passive. Consequently, this may result in higher levels of radicalism across factions of the movement. Because observance is costly, not all members will be content with the increased levels of extremism. This 
result appears to confirm Crenshaw's hypothesis (2001) that competition among groups leads to an escalation of terrorist activities as groups try to outdo one another. In the present case, the outcome is a consequence of leaders' maintaining rents in the face of increased rivalry. If, however, we allow for a wider variety of possible interactions between factions, Crenshaw's hypothesis may not hold. An example was provided by Siqueira (2005), who allowed for a broad variety of externalities to exist between a political faction and a militant terrorist faction. Our brief sketch of his model is limited to two symmetric scenarios.

We let the militant and political wings be indexed by $i=m, p$ and assume that each faction solves the free-riding problem with respect to its own members. The preferences of each faction are represented by

$$
U^{i}=U^{i}\left(q^{i}, Q, x^{i}\right)
$$

where $Q$ is the public good (gain) with respect to the movement and $x^{i}$ is the wing's private consumption. $Q$ equals the weighted summation of the contributions to the movement that stem from the wings' activities (i.e., $Q=\delta q^{m}+q^{p}$, where $q^{m}$ and $q^{p}$ represent the individual wings' contributions and $\delta$ is an exogenous parameter). The latter measures the effectiveness of the militant wing's contributions to the movement. Each wing's contributions is an increasing concave function of its own activities $(t$ and $s): q^{m}=q^{m}(t)$ and $q^{p}=q^{p}(s)$. An increase in the political wing's activities, for example, increases its contribution to the public good, as well as its own well-being.

The resource constraint for each wing is given by

$$
x^{m}+c^{m}(t)=e^{m}+m(t, s)
$$

and

$$
x^{p}+c^{p}(s)=e^{p}+n(s, t)
$$

where $e^{m}$ and $e^{p}$ are initial endowments belonging to the two factions and $c^{m}(t)$ and $c^{p}(s)$ are their respective cost functions. The resource functions for the militant and political factions are given by $m(t, s)$ and $n(s, t)$, and depend on their own activities as well as those of the other wing. Let each function be increasing with respect to its activities, reflecting the fact that a wing's activities also help to finance and support its operations. The second argument in each of these functions captures possible external effects (interdepencies) that may exist between the two wings as a result of their activities. Of the two scenarios that we describe, the first involves mutually reinforcing actions, or strategic complements, so that $m_{s}, n_{t}, m_{t s}=m_{s t}$, and $n_{s t}=n_{t s}$ all have positive signs, where subscripts denote the first and second partial derivatives. The second scenario represents the opposite case, where the signs of the partials are all negative so that the actions of each wing can be viewed as mutually interfering or strategic substitutes. 
In the first scenario, the activities of one wing not only generate resources for the other but also strategically enhance the other wing's agenda. The first scenario thus depicts when there may be strong underlying demand among the movement's supporters for both types of activities. Alternatively, the second scenario indicates when the wings' activities are competitive and driven by rivalry. One faction's activities not only detract and take resources away from the other faction but are also strategic substitutes.

Combining the expressions for $Q, q^{m}, q^{p}$ and each faction's resource constraint in a linear representation of the utility function, we can write each faction's utility as

$$
U^{m}=(1+\delta) q^{m}(t)+q^{p}(s)+e^{m}+m(t, s)-c^{m}(t)
$$

and

$$
U^{p}=\delta q^{m}(t)+2 q^{p}(s)+e^{p}+n(s, t)-c^{p}(s)
$$

If each faction acts independently, then each chooses its activities to maximize its well-being while taking the other faction's activities as a given. The noncooperative Nash equilibrium follows from simultaneously solving the two first-order conditions. With the first scenario of strategic complements, both factions' best-response paths are upward sloping; however, they are downward sloping in the second scenario of strategic substitutes. In either case, the noncooperative outcome can be compared to the cooperative outcome, which follows when both factions act as a single entity and account for all impacts of their activities on the group.

Several results are of interest. For strategic complements, enhanced cooperation among terrorist factions results in greater activities by both factions; for strategic substitutes, enhanced cooperation among factions may favor the activities of one faction. The analysis has implications for counterterrorism policy. A piecemeal counterterrorism policy can be effective under the first scenario, even though the factions act independently. If a government effectively targets the actions of a single faction, the other faction may reduce it activities owing to complementarity. For strategic substitutes, a piecemeal counterterrorism policy may have undesirable consequences if the reduced activities of the targeted faction lead to greater activities of the other faction. One lesson for counterterrorism policy is that governments must account for the various interactions among factions within the terrorist movement. This requires intelligence on the terrorist movement, its constituent parts, and how the factions' activities are viewed by its supporters.

Many questions remain. We are still in the dark about the dynamics that cause terrorist groups to fracture. For fractured groups, we need to understand how they maintain a level of coordination - for instance, the Palestine Liberation Organization ties Palestinian groups that have split off from Fatah and other groups. Investigating the latter is an initial step to understanding how a group's structure affects the policies and behavior of its various factions. 


\section{Games of Asymmetric Information}

Owing to the covert nature of terrorism, participants find themselves in situations where they have less-than-perfect information. A government, for example, may be uncertain about the objectives, capabilities, and resources associated with the terrorist groups that it faces. Similarly, a terrorist group may be unsure about the resolve of its targeted government. In other circumstances, one party may be unable to observe whether the other party has devoted sufficient effort to live up to its side of an agreement.

Lapan and Sandler (1993) analyzed the circumstances under which a signaling game results when a government is uniformed about a terrorist group's resources. Terrorist groups with limited resources may appear stronger than they are through large initial attacks, intended to induce concessions from an ill-informed government. A government must use past attacks as signals to update its beliefs about the terrorists' true strength. The government must then decide whether to concede to a terrorist group on the basis of the government's updated priors and its expected costs from enduring future attacks if it holds its ground.

Terrorist resources are assumed to be storable across periods but have no value in alternative use (Lapan \& Sandler, 1993). As in most signaling games, several types of equilibriums are possible. For example, a pooling equilibrium (where the government cannot distinguish among groups) exists in which the government chooses to never concede and all terrorist groups, regardless of resources, choose to spend their resources immediately and attack the government. A partial separating equilibrium may also exist in which the government concedes only to groups whose level of attacks exceeds a threshold.

In a related analysis by Overgaard (1994), terrorist resources are discrete, perishable but renewable, and valuable in uses other than terrorism. The author showed that a unique separating equilibrium exists and that depending on the flexibility of government responses, a pooling equilibrium may also exist. Because all private information is revealed at the separating equilibrium, there is no ex post regretwhen the government regrets its concessions once the true type of terrorist is revealed (Lapan \& Sandler, 1993).

In Arce and Sandler's work (2007), the government is uncertain whether the terrorist group is political or militant. Under their assumptions, a group is politically motivated if its resources are assigned to political uses when the government is unrelenting to the group's demands. In contrast, a militant group prefers to put all its resources into an attack even when the government holds firm. Thus, the authors incorporated aspects of both Lapan and Sandler's work (1993) and Overgaard's (1994). Not only does Arce and Sandler's separate treatment of the likely characteristics of a terrorist movement give a more nuanced policy environment with which to analyze the interaction between terrorists and the government, but their distinction 
also adds meaning to the value of intelligence. With respect to the former, a defensive policy may encourage intertemporal substitution by militants as they delay the attack until a later date to catch the government unaware. A more proactive policy, however, directly affects the level of terrorist resources and therefore alters the nature of the resulting pooling and separating equilibriums. The value of intelligence is greater in a more diverse environment, where terrorist motivations may vary. Intelligence has value to minimize two forms of regret: first, conceding to political terrorists who will not attack beyond its initial campaign and, second, failing to concede to militant terrorists who will continue attacks in the absence of concessions. ${ }^{5}$

The problem of asymmetric information and strategic behavior can occur when two parties are essentially working to achieve similar goals, as in the work by Bueno de Mesquita (2005b, 2007) and Shapiro and Siegal (2007). Such situations are known as problems of agency, where a principal cannot observe an agent's effort and so must devise a scheme to make high effort a dominant strategy. In Bueno de Mesquita's article (2005b), discussed earlier, the government is unable to ascertain the ability and the amount of effort that its potential partners, former terrorists, exert in their combined fight against terrorism. Shapiro and Siegal represented the terrorist leader as being unable to monitor agent behavior because of the inherent nature of its covert operations. Although the terrorist leader and the terrorist middleman care about mission success, their interests diverge because the latter may profit from using operation funds for self-aggrandizement. Because the game between the terrorist leader and the middleman is potentially repeated, the leader can discipline the middleman on the basis of past performance and so deny him gains from future participation. Given stylized assumptions concerning players' strategies, the authors demonstrated that the middleman is retained after a successful attack but dismissed after a failure. The authors showed that there are four equilibrium outcomes; in two of which, either all or none of the money allocated toward an attack is skimmed by the middleman. In the breakdown equilibrium, where skimming is complete, the leader obtains the same attack success probability as he does when no money is provided. Insofar as disbursing funds is costly to the leader, the leader is better off not doing so. For the honest equilibrium, the middleman is sufficiently motivated by the terrorist cause and gives up skimming entirely. An interior solution is also possible with partial skimming, where the leader benefits sufficiently to delegate responsibility for the attack despite the diversion of funds. One of the more interesting findings is that agency problems within terrorist organizations limit not only the effectiveness of such organizations but also the effectiveness of government counterterrorism policies. Until a critical lower threshold of available funds is reached, an organization that carefully allocates funding in the face of a potentially venal middleman is already somewhat invulnerable to government policies designed to restrict its sources of funding. 


\section{Multiagent, Multistage Games Involving Terrorism}

In recent years, there has been interest in multiagent, multistage games involving terrorists and other participants (e.g., Bueno de Mesquita, 2007; Siqueira, 2005; Siqueira \& Sandler, 2006, 2007). These games may allow for leader-follower and simultaneous strategic interactions. For leader-follower interactions, the player in a preceding stage optimizes with respect to the anticipated reaction of the follower in the subsequent stage. When strategic interactions are simultaneous, each strategic player takes the other player's action as a given so that a Nash-Cournot conjecture and a Nash equilibrium apply. Not all players in these multistage games are strategic; in fact, the players in the final stage are often passive- that is, they are reactive players who optimize what is presented to them from earlier stages. At a given stage, there are typically no more than two kinds of players, though there may be many players of the same type. Three strategic players could characterize the same stage, but that would require a good deal of modeling ingenuity. Multistage games easily allow for three strategic players, with less modeling complexity than that of a single-stage game. It is, however, important that the sequence of plays and stages appear natural; that is, governments fortify venues before terrorists decide which target to strike.

In Table 2, we indicate the stages and participants associated with two recent game analyses of terrorism, discussed earlier. The strategic players, the type of strategic interaction, and the passive players are identified. Both leader-follower and simultaneous interactions are relevant, with one or two player types at a given stage. Future analyses will see more strategic players at a given stage and, thus, more active players associated with between-stage interactions.

\section{Suicide Terrorism and Game Theory}

The application of game theory to suicide terrorism may seem inappropriate because game theory assumes rational players. In recent years, suicide terrorists are, however, viewed as comprising rational players whose acts of self-sacrifice further group goals in organized terrorist campaigns (Enders \& Sandler, 2006; Pape, 2005). Suicide terrorists display high logistical success rates and kill 12 times as many people as a conventional terrorist attack does (Pape, 2005). The rationality of suicide terrorists is founded on the notion that they view the expected utility of their sacrificial attack to exceed the expected utility of living. The former expected utility may be bolstered by some or all of the following: rewards in the afterlife afforded to a martyr (Berman \& Laitin, 2005), the prestige and camaraderie accorded to the bomber before the suicide mission (Wintrobe, 2006), the altruism gained from providing a public good to future generations (Azam, 2005), and/or payments given to the terrorist's family after the mission (Berman \& Laitin, 2005). 
Table 2

Two Examples of Multiagent, Multistage Games

Siqueira and Sandler (2006)

Stage 1: Terrorist sponsor chooses the level of sponsorship.

Strategic leadership role with the terrorists and government

Stage 2: Terrorists choose their campaign, whereas the government chooses counterterrorism and public services.

Both players are strategic vis-à-vis their adversary.

Both players move simultaneously as Nash players.

Both vie for public support.

Stage 3: Population decides its allegiance based on public services, terrorist success, and government counterterrorism.

Population members are passive, nonstrategic players.

Siqueira and Sandler (2007)

Stage 1: Strategic voting by representative voter in each of two targeted countries to elect a policy maker

Strategic leadership role with the policy maker

Stage 2: Elected policy makers in each of two countries decide their proactive response, given their perceived response from the terrorists.

Policy makers are strategic vis-à-vis their counterparts.

Policy makers move simultaneously as Nash players.

Policy makers prefer not to draw a backlash attack.

Stage 3: Two different terrorist groups decide which country to attack on the basis of policy makers' Stage 2 decisions.

Both terrorist groups are passive, nonstrategic players.

The players in a terrorist game of suicide may include various agent combinations: terrorist operatives (Azam, 2005; Jain \& Mukand, 2004); the suicide bomber and the terrorist organization's leader (Berman \& Laitin, 2005); the government and the terrorist organization (Enders \& Sandler, 2004; Jacobson \& Kaplan, 2007); the government, the terrorist operatives, and the terrorist organization (Bueno de Mesquita, 2005c). In some analyses, the strategic interaction is implicit because it is not truly modeled - for instance, in the work by Enders and Sandler (2004) and Wintrobe (2006). A common challenge of these theoretical representations is to display the choice between regular bombings and suicide bombings, where the latter imply a corner solution in which the terrorist ends his or her life for the cause (Azam, 2005; Enders \& Sandler, 2004; Wintrobe, 2006). The equilibrium may involve the terrorists being sorted into three activities-no bombings, conventional bombings, and suicide bombings-depending on their preferences. In Azam's article (2005), only those terrorists who are the most altruistic toward the future generations partake in suicide missions intended to bring about a political change. As such, this change is described as an intergenerational public good whose benefits are received by all subsequent generations. Thus, the American revolutionaries provided civil and political freedoms for future generations through their sacrifices. 
The public good that derives from a successful terrorist campaign presents a freerider problem. Earlier-mentioned motivators (e.g., heavenly rewards, prestige, camaraderie) augment the terrorist's personal utility from a suicide mission, thereby addressing the free-riding problem. If, however, these bomber-specific gains are not sufficient, then a potential bomber will choose to sit back and profit from another's sacrifice. The terrorist organization acts strategically to augment these individual gains or reduce the bomber's logistical costs to motivate a sacrifice for the good of the group.

At a corner solution, the terrorist views his or her anticipated marginal benefit as exceeding the associated marginal cost for all levels of resource expenditure, even that involving one's life. The presence of a corner solution means that governmental policy changes that marginally alter the price of terrorists' actions may have no impact on the suicide bomber; thus, small changes in deterrence that make suicide bombings more difficult may achieve little. Effective policies must either involve large deterrents or else get at the terrorists' motivation. If, for the latter, the terrorist is driven by intergenerational altruism, then harsh measures by a targeted government to limit intergenerational transfers may be effective (Azam, 2005). Hence, the Israeli authorities take stringent actions against the family of the suicide bombers.

Krueger and Maleckova (2003) noted that suicide terrorists tend to display education levels higher than those of their cohort population. When canvassing for operatives, terrorist organizations use education as a screening device for operatives who can accomplish the complex mission of a suicide bombing. Azam (2005) indicated that education is positively related to intergenerational altruism. As such, Azam cautioned against foreign assistance for some terrorism-ridden countries, because by raising education levels, it may encourage more suicide bombings. In contrast, Bueno de Mesquita (2005c) showed that foreign assistance may have opposing effects because higher income raises the opportunity costs of suicide bombers and augments the quality of potential attackers through education. He also demonstrated that counterterrorism has opposing influences: It augments anger and reduces economic opportunities, both of which encourage terrorism, and it makes missions more difficult, which inhibits attacks. If the negative economic consequences of counterterrorism are sufficiently large, then less counterterrorism may reduce suicide missions. Intermediate levels of counterterrorism may be best (Jacobson \& Kaplan, 2007; Rosendorff \& Sandler, 2004); that is, small counterterrorism levels allow terrorists to act with impunity, whereas large counterterrorism levels result in recruitment and backlash.

Although the models differ, they share some common themes. First, suicide missions imply corner solutions where standard (marginal) policy interventions may be ineffective. Second, suicide terrorists tend to be well educated. Third, hardened targets are more apt to attract suicide bombers. Fourth, income assistance may not reduce suicide attacks, owing to opposing influences. Fifth, government must at times seek to give potential terrorist operatives those things provided by terrorist organizations - that is, a sense of social cohesion and social services. Sixth, terrorist organizations must circumvent a free-rider problem. In Table 3, we highlight six recent studies in terms of their modeling strategy and findings. Many of these 
findings are surprising until the strategic interactions of the agents are understood (e.g., hardened targets require terrorists to dispatch their most destructive agents). The conclusions are sensitive to the setup of the game, including the sequence of plays and the set of players. Contrary findings stem from such differences.

\section{Concluding Remarks}

As shown herein, many important aspects of terrorism have been illuminated in recent years by game-theoretic studies. These investigations resulted in many nonobvious propositions that are consistent with real-world observations-for example, hardened targets attract suicide bombers; standard policies do not deter suicide bombers; a high-cost defender is the likely country to address a common transnational terrorist threat; and defenders are better off making their defense allocations public. Despite many new insights, important issues remain unanswered.

More analysis is needed on the allocation of counterterrorism resources within the broad categories of defensive and proactive measures. That is, the allocation among intelligence, target hardening, and proactive raids is still poorly understood when the targeted governments and the terrorists are strategic players. Current analyses presume just a domestic terrorist threat so that the interplay among targeted governments is ignored. The interaction between terrorists and a targeted government needs to be further investigated in a dynamic framework where terrorist success and failure influence terrorist recruitment and resource accumulation. Jacobson and Kaplan (2007) presented an initial dynamic paradigm to investigate Israeli actions against a suicide terrorist campaign. Their study addressed one kind of government response-targeted assassinations. This modeling exercise can be expanded in many fruitful directionsfor instance, the inclusion of the support population as a strategic agent.

The strategic interaction within terrorist groups can be expanded to allow the government to be a strategic player who takes advantage, when possible, of conflict between different terrorist factions. Researchers should ultimately develop a gametheoretic model explaining the transformation and schism of terrorist groups over time. If these factors are understood, then government actions can hasten groups' demise and resist measures that create more formidable splinter groups.

Researchers can develop additional agency-based models where asymmetric information is incorporated into the model. A theory of franchising is needed where a sponsor, such as al-Qaida, funds other groups' operations. Of course, the franchiser has less information than does the group receiving support. In other instances, a common-agency problem arises when a terrorist group (e.g., Abu Nidal Organization) hires itself out to different sponsors with diverse political objectives. The most effective counterterrorism policy in such a situation is not well understood.

Much remains to be done to model suicide terrorism. To date, there is no model that incorporates diverse strategic agents in a framework that accounts for a corner solution. Azam's model (2005) accounts for corner solutions, but his strategic agents 


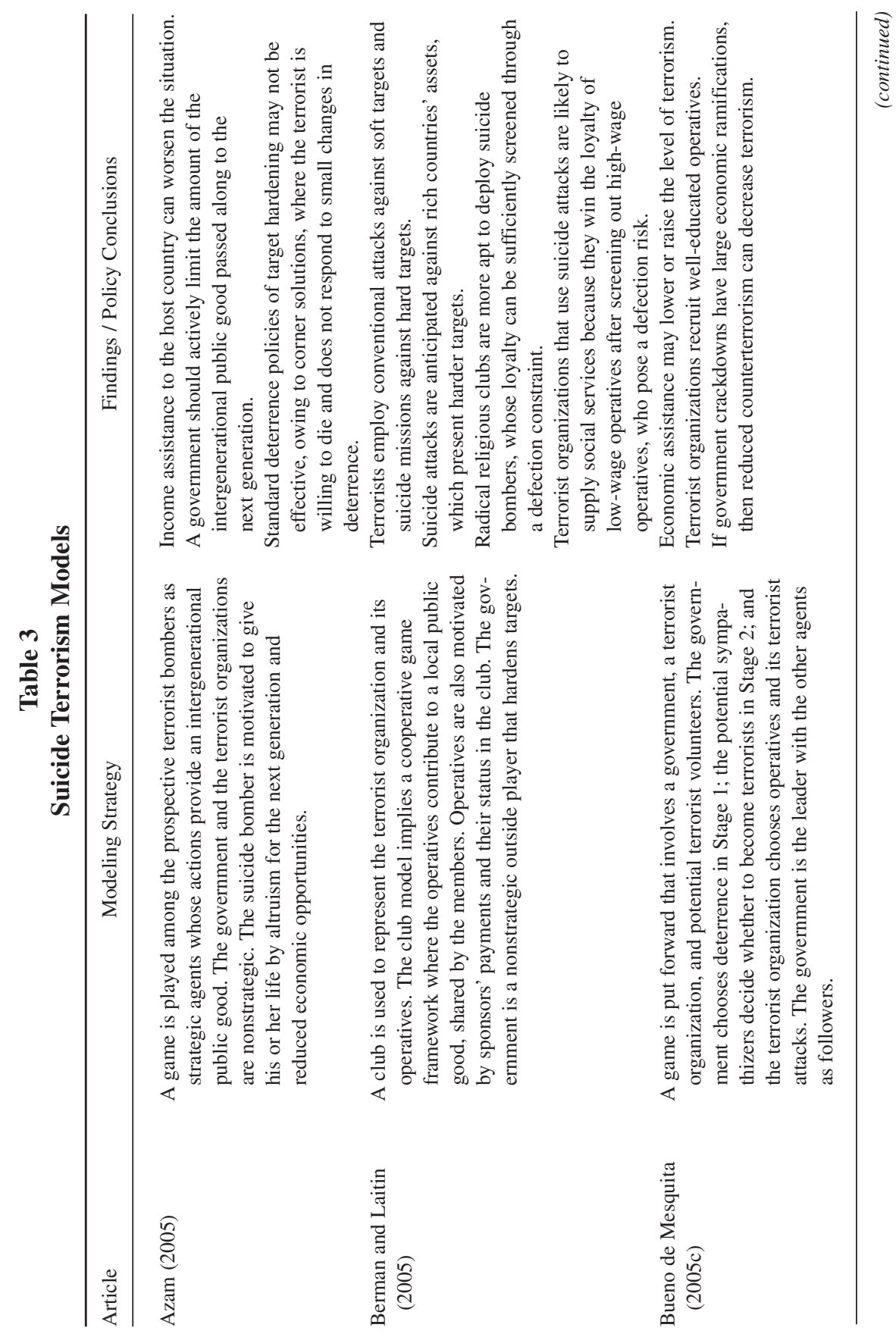




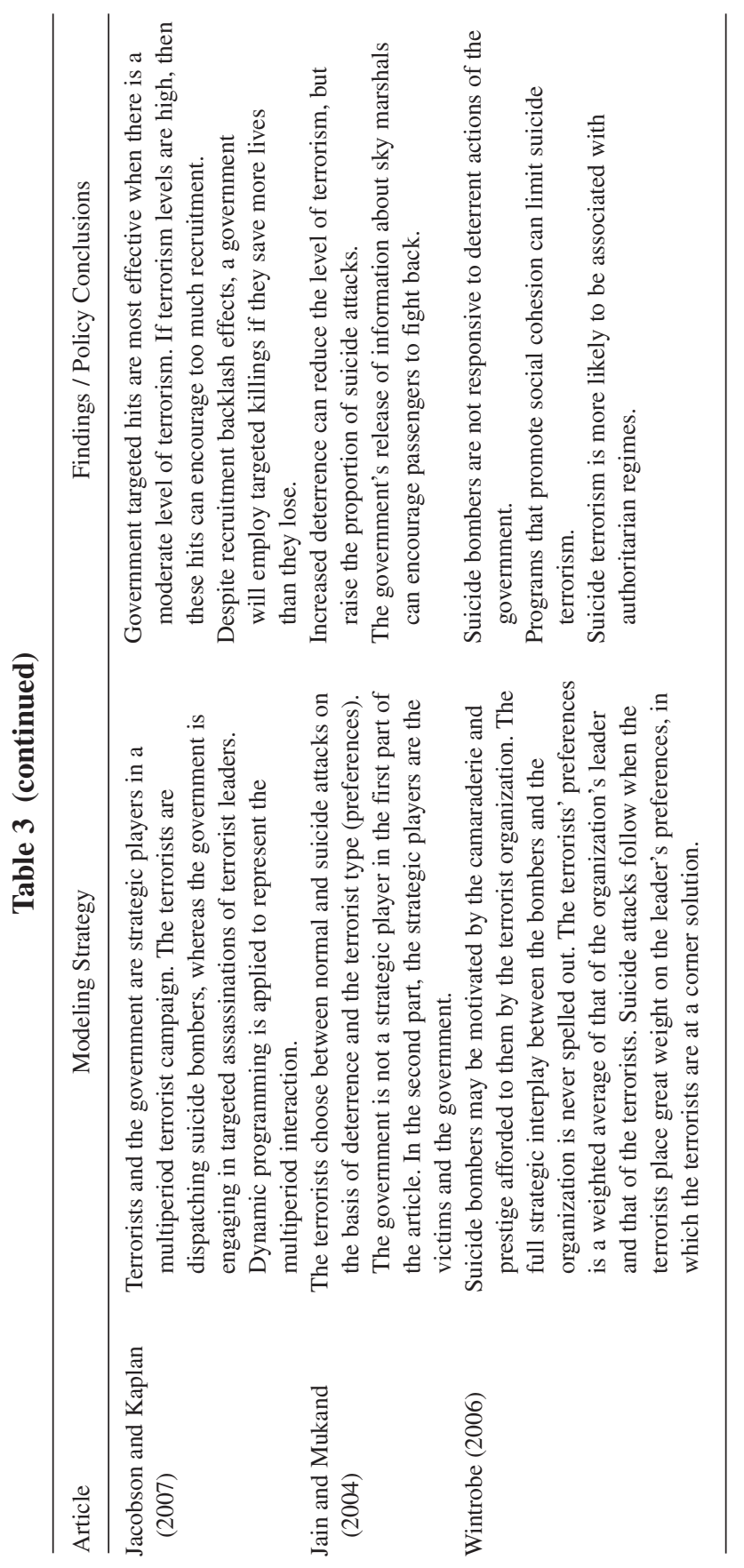


comprise just one type (the terrorists); however, Bueno de Mesquita's model (2005c) has diverse strategic agents but do not address corner solutions. A marriage of these two modeling strategies is needed.

Finally, game theory should address the strategic interaction of the media, the terrorists, and the public in a three-player game. The media and the terrorists have a symbiotic relationship because large-scale terrorist incidents give terrorists the publicity that they seek and these events provide the media with a larger audience and, thus, more profit. Rohner and Frey (2007) presented a two-player static game and dynamic game with just the media and the terrorists as players. Equilibriums consist of (a) no attacks and no media reporting or (b) terrorists's specializing in attacks and the media's covering terrorism to the exclusion of other news. Neither equilibrium jives with the real world. A more descriptive analysis will come from the addition of a third strategic player - the public or the government — that can add an offset to the symbiotic relationship between the media and the terrorists.

\section{Notes}

1. In subsequent work, Zhuang and Bier (2008) generalized their analysis by allowing the defender and the attacker to be ill-informed; that is, the defender does not know the terrorists' capabilities, whereas the attacker does not know the defense allocations. The authors showed that with two-sided uncertainty, equilibrium allocations may involve defenders' deception, secrecy, or full disclosure, depending on the signaling costs and the value of protected assets. Secrecy or deception may be the best course of action, owing to the endogenous reaction of the ill-informed attacker. Dighe, Zhuang, and Bier (2007) examined the advantage of partial secrecy involving the disclosure of total defense allocation but not its specific assignment among potential targets.

2. Strategic complements involve choice variables where one player's increase induces the other player to follow suit. In contrast, strategic substitutes concern decisions where one player's increase causes the other player to reduce its level of the same variable.

3. Under some scenarios, defensive policies can be strategic substitutes with negatively sloped reaction paths. This is the case when a country's assets are equally vulnerable at home or abroad. In contrast, proactive measures are always strategic substitutes.

4. These authors published a number of articles about interdependent risk. Heal and Kunreuther (2005) is representative of their line of reasoning.

5. Not all games of asymmetric information in the terrorism literature have terrorist type as being uncertain. For example, in Bueno de Mesquita and Dickson (2007), the government can be either hard-line or soft-line. For this three-player multistage game, terrorists decide whether to launch a terrorist campaign to provoke a harsh government response that may result in greater support from an aggrieved population. The authors displayed four equilibriums: two pooling equilibriums and two separating equilibriums.

\section{References}

Alexander, Y., \& Pluchinsky, D. (1992). Europe's red terrorists: The fighting communist organizations. London: Frank Cass.

Arce, D. G., \& Sandler, T. (2005). Counterterrorism: A game-theoretic analysis. Journal of Conflict Resolution, 49(2), 183-200. 
Arce, D. G., \& Sandler, T. (2007). Terrorist signalling and the value of intelligence. British Journal of Political Science, 37(4), 573-586.

Azam, J.-P. (2005). Suicide-bombing as inter-generational investment. Public Choice, 122(1-2), 177-198.

Bandyopadhyay, S., \& Sandler, T. (2007). The interplay between preemptive and defensive counterterrorism measures: A two-stage game. Unpublished manuscript, University of Texas at Dallas.

Berman, E., \& Laitin, D. D. (2005). Hard targets: Theory and evidence on suicide attacks (Working Paper No. 11740). Cambridge, MA: National Bureau of Economic Research.

Bier, V. M., Oliveros, S., \& Samuelson, L. (2007). Choosing what to protect: Strategic defensive allocation against an unknown attacker. Journal of Public Economic Theory, 9(4), 563-587.

Bueno de Mesquita, E. (2005a). Conciliation, commitment and counterterrorism: A formal model. International Organization, 59(1), 145-176.

Bueno de Mesquita, E. (2005b). The terrorist endgame: A model with moral hazard and learning. Journal of Conflict Resolution, 49(2), 237-258.

Bueno de Mesquita, E. (2005c). The quality of terror. American Journal of Political Science, 49(3), 515-530.

Bueno de Mesquita, E. (2007). Politics and the suboptimal provision of counterterror. International Organization, 61(1), 9-36.

Bueno de Mesquita, E., \& Dickson, E. S. (2007). The propaganda of the deed: Terrorism, counterterrorism, and mobilization. American Journal of Political Science, 51(2), 364-381.

Crenshaw, M. (2001). Theories of terrorism: Instrumental and organizational approaches. In D. C. Rapoport (Ed.), Inside terrorist organizations (pp. 13-31). London: Frank Cass.

Dighe, N., Zhuang, J., \& Bier, V. M. (2007). Secrecy in defensive allocations as a strategy for achieving more cost-effective attacker deterrence. Unpublished manuscript, University of Wisconsin, Madison.

Enders, W., \& Sandler, T. (1993). The effectiveness of anti-terrorism policies: Vector-autoregressionintervention analysis. American Political Science Review, 87(4), 829-844.

Enders, W., \& Sandler, T. (2004). What do we know about the substitution effect in transnational terrorism? In A. Silke (Ed.), Research on terrorism: Trends, achievenments and failures (pp. 119-137). London: Frank Cass.

Enders, W., \& Sandler, T. (2006). The political economy of terrorism. Cambridge: Cambridge University Press.

Epstein, G. S., \& Gang, I. N. (2007). Understanding the development of fundamentalism. Public Choice, 132(3-4), 257-271.

Farrow, S. (2007). The economics of homeland security expenditures: Foundational expected costeffectiveness approaches. Contemporary Economic Policy, 25(1), 14-26.

Garfinkel, M. R. (2004). Global threats and the domestic struggle for power. European Journal of Political Economy, 20(2), 495-508.

Heal, G., \& Kunreuther, H. (2005). IDS models of airline security. Journal of Conflict Resolution, 49(2), 201-217.

Hoffman, B. (2006). Inside terrorism (Rev. ed.). New York: Columbia University Press.

Jacobson, D., \& Kaplan, E. H. (2007). Suicide bombings and targeted killings in (counter-) terror games. Journal of Conflict Resolution, 51(5), 772-792.

Jain, S., \& Mukand, S. W. (2004). The economics of high-visibility terrorism. European Journal of Political Economy, 20(2), 479-494.

Krueger, A. B., \& Maleckova, J. (2003). Education, poverty, and terrorism: Is there a causal connection? Journal of Economic Perspectives, 17(4), 119-144.

Lapan, H. E., \& Sandler, T. (1993). Terrorism and signalling. European Journal of Political Economy, 9(3), 383-397.

Lee, S. (2007). Counterterrorism alliance. Unpublished manuscript, City College of New York.

Olson, M. (1965). The logic of collective action. Cambridge, MA: Harvard University Press.

Overgaard, P. B. (1994). The scale of terrorist attacks as a signal of resources. Journal of Conflict Resolution, 38(3), 452-478.

Pape, R. A. (2005). Dying to win: The strategic logic of suicide terrorism. New York: Random House. 
Powell, R. (2007). Defending against terrorist attacks with limited resources. American Political Science Review, 101(3), 527-541.

Rohner, D., \& Frey, B. S. (2007). Blood and ink! The common-interest-game between terrorists and the media. Public Choice, 133(1-2), 129-145.

Rosendorff, B. P., \& Sandler, T. (2004). Too much of a good thing? The proactive response dilemma. Journal of Conflict Resolution, 48(5), 657-671.

Sandler, T., \& Arce, D. G. (2003). Terrorism and game theory. Simulation \& Gaming: An International Journal, 34(3), 319-337.

Sandler, T., \& Lapan, H. E. (1988). The calculus of dissent: An analysis of terrorists' choice of targets. Synthèse, 76(2), 245-261.

Sandler, T., \& Siqueira, K. (2006). Global terrorism: Deterrence versus pre-emption. Canadian Journal of Economics, 39(4), 1370-1387.

Sandler, T., Tschirhart, J. T., \& Cauley, J. (1983). A theoretical analysis of transnational terrorism. American Political Science Review, 77(4), 36-54.

Shapiro, J. N., \& Siegel, D. A. (2007). Underfunding in terrorist organizations. International Studies Quarterly, 51(2), 405-429.

Siqueira, K. (2005). Political and militant wings within dissident movements and organizations. Journal of Conflict Resolution, 49(2), 218-236.

Siqueira, K., \& Sandler, T. (2006). Terrorists versus the government: Strategic interaction, support, and sponsorship. Journal of Conflict Resolution, 50(6), 878-898.

Siqueira, K., \& Sandler, T. (2007). Terrorist backlash, terrorism mitigation, and policy delegation. Journal of Public Economics, 91(9), 1800-1815.

Siqueira, K. \& Sandler, T. (forthcoming). Defensive counterterrorism measures and domestic politics. Defence and Peace Economics, 19.

Tucker, A. (2001). A two-person dilemma. In E. Rasmussen (Ed.), Readings in games and economics (pp. 7-8). Malden, MA: Blackwell. (Orignal work published 1950)

Tullock, G. (1974). The social dilemma: The economics of war and revolution. Blacksburg, VA: University Publications.

Wilkinson, P. (1986). Terrorism and the liberal state (Rev. ed.). London: Macmillan.

Wintrobe, R. (2006). Extremism, suicide terror, and authoritarianism. Public Choice, 128(1), 169-195.

Zhuang, J., \& Bier, V. M. (2007). Balancing terrorism and natural disasters-Defensive strategy with endogenous attacker effort. Operations Research, 55(5), 976-991.

Zhuang, J., \& Bier, V. M. (2008). Modeling secrecy and deception in homeland security resource allocation. Unpublished manuscript, University of Wisconsin, Madison.

Todd Sandler is the Vibhooti Shukla Professor of Economics and Political Economy, University of Texas at Dallas. He has used game theory in the study of terrorism since 1983. In 2003 he was corecipient of the National Academy of Sciences' Estes award for excellence in science for his research on terrorism. He directs the Center for Global Collective Action. Contact: School of Economic, Political \& Policy Sciences, University of Texas at Dallas, GR31, 800 W. Campbell Road, Richardson, TX 75080-3021, USA; +1 972-883-6725 (t); +1 972-883-6486 (f); tsandler@utdallas.edu.

Kevin Siqueira is an associate professor of economics,University of Texas at Dallas. He has applied game theory to terrorism and to the study of the environment. His teaching and research interests involve many aspects of game theory. Contact: School of Economic, Political \& Policy Sciences, University of Texas at Dallas, GR31, 800 W. Campbell Road, Richardson, TX 75080-3021, USA; +1 972-883-6480 (t); +1 972-883-6486 (f). 